\title{
Surrogate motherhood in illness that does not cause infertility
}

\author{
D W Jordaan, $\mathrm{PhD}$ \\ Department of Jurisprudence, College of Law, University of South Africa
}

Corresponding author: D W Jordaan (mail@donrichjordaan.law.za)

The threshold requirement for surrogate motherhood requires that a commissioning parent or parents are permanently unable to give birth to a child. The question has arisen of a commissioning mother who suffers from a permanent illness that does not cause infertility but that renders pregnancy a significant health risk to her and/or to her prospective child in utero. The threshold requirement inability to give birth to a child should not be interpreted narrowly as referring only to a commissioning parent's inherent inability to give birth to a child, but should be interpreted broadly as referring only to a commissioning parent's effective inability to give birth to a child - allowing consideration of the medical sequelae of pregnancy for the commissioning mother and her prospective child. A broad interpretation of the threshold requirement is compatible with legislative intent, case law and our constitutional commitment to human rights.

S Afr Med J 2016;106(6):684-685. DOI:10.7196/SAMJ.2016.v106i7.10668

Surrogate motherhood in South Africa (SA) is regulated by the Children's Act, ${ }^{[1]}$ the National Health Act ${ }^{[2]}$ and its regulations, ${ }^{[3]}$ and court cases. ${ }^{[4-6]}$ The Children's Act formulates the legal requirement for a commissioning parent or parents to legally access surrogacy: ${ }^{[1]}$

'A court may not confirm a surrogate motherhood agreement unless - (a) The commissioning parent or parents are not able to give birth to a child and that the condition is permanent and irreversible.

I refer to this as the 'threshold requirement' for surrogate motherhood, following the judgment in $A B$ and Another $v$ Minister of Social Development. ${ }^{[6]}$ Persons qualifying in terms of the threshold requirement include male same-sex couples and single men (who are biologically unable to give birth) and heterosexual couples or single women where the woman is medically unable to carry a pregnancy to term. However, in the case of LS (unreported case, High Court of South Africa, Gauteng Local Division, Johannesburg, Case No.: 2015/24392.), the commissioning parents who applied to have their surrogacy agreement confirmed by the court were a heterosexual couple, and the commissioning mother was fertile but had a permanent illness that, according to medical expert evidence, would render pregnancy a significant risk to her health and that of the prospective child's health in utero. Should this couple qualify for surrogate motherhood in terms of the threshold requirement?

\section{Interpretations of the threshold requilrement}

A narrow interpretation of the threshold requirement would focus only on a person's inherent ability to carry a successful pregnancy, and exclude considering the medical sequelae of pregnancy; a broad interpretation would consider the medical sequelae of pregnancy as integral to the person's ability to give birth to a child.

\section{Legislative history}

In 1987, the then SA Law Commission (SALC) investigated surrogate motherhood, culminating in a report in 1992. ${ }^{[7]}$ This report made comprehensive recommendations for the statutory regulation of surrogate motherhood. ${ }^{[7]}$ The origins of the threshold requirement appear from the following recommendations: ${ }^{[7]}$
'The view of medical doctors is that surrogate motherhood is a form of medically assisted procreation that is usually only considered as a last option. This view is based on the medical, ethical and legal issues involved. Owing to all the risk factors inherent in surrogate motherhood, this option should only be available as a last resort.'

'A surrogate motherhood agreement should not be permitted unless it is proved that owing to a medical situation, the commissioning wife is unable to give birth to a child.'

In 1994, a parliamentary ad hoc committee (the 'Ad Hoc Committee') was established to enquire into and report on the SALC Report. The changes that the Ad Hoc Committee recommended to the recommendations of the SALC included, among others, the inclusion of unmarried couples (irrespective of their sexual orientation) and single persons into those who can access surrogacy. They retained the requirement that surrogacy should only be exercised as 'remedy of last resort': ${ }^{[8]}$

'Surrogacy should only be exercised as a remedy of last resort because of all the risk factors which are inherent in surrogate motherhood. The Committee concurs with the SA Law Commission's recommendation that a surrogacy agreement should not be permitted unless it is proved that owing to biological or medical factors the commissioning parent or parents are unable to give birth to a child and that condition must be permanent and irreversible.'

The legislative intent of the threshold requirement was to exclude surrogacy for convenience and restrict surrogacy to a reproductive remedy of last resort. The wording 'not able to give birth' was designed to give effect to such legislative intent. The SALC Report and the Ad Hoc Committee's Report did not consider the differentiation between the narrow and the broad interpretations of the threshold requirement.

\section{No answers in case law}

The leading case law on the confirmation of surrogate motherhood agreements by the High Court, namely Ex Parte WH and Others ${ }^{[4]}$ 
and Ex Parte MS and Others, ${ }^{[5]}$ deals with situations where the commissioning parents were unable to give birth to a child. In $\mathrm{WH},{ }^{[4]}$ the commissioning parents were a male same-sex couple and biologically unable to give birth; in $\mathrm{MS}^{[5]}$ the commissioning parents were a heterosexual couple, but the woman was diagnosed with infertility after several in vitro fertilisation attempts ended in miscarriage. The fulfilment of the threshold requirement was apparent, and the issue of the interpretation of the threshold requirement as either narrow or broad was not relevant and hence not considered.

The interpretation of the threshold requirement also did not arise in the case of $\mathrm{AB},{ }^{[6]}$ which challenged the validity of another statutory requirement for surrogate motherhood based on constitutional grounds.

In the case of LS, the Court decided in favour of the commissioning couple to grant the application for confirmation of the surrogate motherhood agreement but provided no reasons, therefore not establishing a precedent regarding the interpretation of the threshold requirement.

\section{The human rights dimension}

Several human rights are relevant in situations similar to the LS case where the commissioning parent or parents are able to give birth to a child, but where such pregnancy, because of a permanent illness, entails significant health risk to the woman or the fetus. Three human rights are human dignity, the right to freedom and security of one's person, and the best interests of the child, which are briefly analysed. In the Certification of the Constitution of the Republic of SA, 1996 ${ }^{[9]}$ the Constitutional Court held that the right to dignity entails the right to establish and raise a family. ${ }^{[10]}$ The threshold requirement intends balancing the right to establish a family with the government purpose of avoiding surrogacy agreements for convenience and of reserving surrogacy as a reproductive means of last resort. In situations similar to the LS case, where there is significant health risk to the commissioning mother or the prospective fetus, recourse to surrogacy is not a matter of convenience and is a reproductive means of last resort.

The right to freedom and security of one's person includes the right not to be treated in an inhuman or degrading way. ${ }^{[10]}$ To expect a commissioning mother to become pregnant to establish a family and to potentially sacrifice her health or that of her child, would be inhuman and degrading.
The best interests of the child demand using a surrogate mother rather than a pregnancy by the commissioning mother: Once born, prospective children have an interest in their own good health and that of their mothers. The Constitution requires that the best interests of the child be paramount in all matters pertaining to the child. ${ }^{[10]}$

Human rights favour the broad interpretation of the threshold requirement. If pregnancy by the commissioning mother entails significant risk to her or the child, she is effectively unable to give birth to a child. A narrow interpretation of the threshold requirement that ignores the consequences of pregnancy would be untenable, as the commissioning mother is significantly compromised: remain childless, or become pregnant and accept the risk - and moral responsibility - of significant health risk to oneself or to one's prospective child. This is an inhuman choice that the law cannot force on any person.

\section{Conclusion}

Pregnancy carries health risks and there are many permanent illnesses that may increase a woman's health risk during pregnancy. Not all health risks would satisfy the threshold requirement and each case should be evaluated on its merits. Only if expert medical evidence indicates that, because of a permanent illness, pregnancy by the commissioning mother would entail significant health risk to either the mother or the prospective child, and she is effectively unable to give birth to a child, should the Court rule that the threshold requirement is fulfilled and allow surrogacy as a reproductive avenue of last resort.

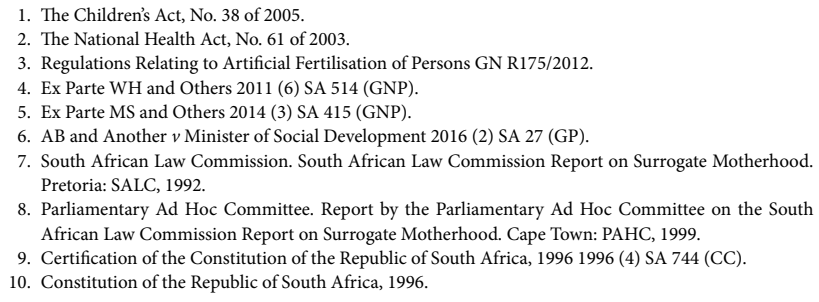

Accepted 22 February 2016. 